WSRC-TR-92-494

\title{
REVISED MINIMUM NITRITE CONCENTRATION FOR ESP
} (U)

WSRC-TR--92-494

by P. E. Zapp

Westinghouse Savannah River Company

DE93 0.11707

Savannah River Site

Aiken, South Carolina 29808

Other Authors:

This paper was prepared in connection with work done under Contract No. DE-AC09-89SR18035 with the U.S. Department of Energy. By acceptance of this paper, the publisher and/or recipient acknowledges the U.S. Government's right to retain a nonexclusive, royalty-free license in and to any copyright covering this paper, along with the right to reproduce and to authorize others to reproduce all or part of the copyrighted paper.

\section{MASTER}




\section{DISCLAIMER}

This report was prepared as an account of work sponsored by an agency of the United States Government. Neither the United States Government nor any agency thereof, nor any of their employees, makes any warranty, express or implied, or assumes any legal liability or responsibility for the accuracy, completeness, or usefulness of any information, apparatus, product, or process disclosed, or represents that its use would not infringe privately owned rights. Reference herein to any specific commercial product, process, or service by trade name, trademark, manufacturer, or otherwise does not necessarily constitute or imply its endorsement, recommendation, or favoring by the United States Government or any agency thereof. The views and opinions of authors expressed herein do not necessarily state or reflect those of the United States Government or any agency thereof.

This report has been reproduced directly from the best available copy.

Available to DOE and DOE contractors from the Office of Scientific and Technical Information, P.O. Box 62, Oak Ridge, TN 37831; prices available from (615) 576-8401, FTS 626-8401.

Available to the public from the National Technical Information Service, U.S. Department of Commerce, 5285 Port Royal Rd., Springfield, VA 22161. 
Key Words: Corrosion, Pitting, Carbon Steel, Sludge Processing. Permanent Retention

October 26, 1992

TO: $\quad$ T. M. Monahon, 703-H

FROM: P. F. Zapp, 773-A P\&-3egp

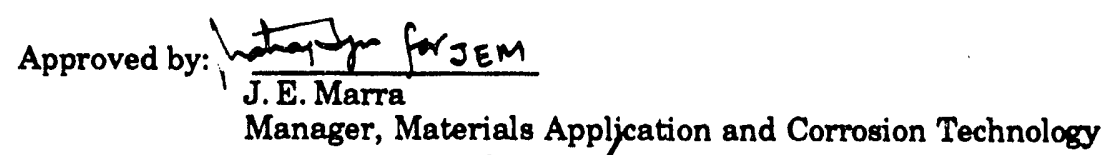

Technically Reviewed by :

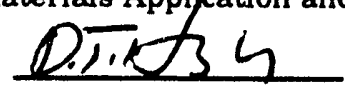

\section{REVISED MINIMUM NITRITE CONCENTRATION FOR ESP(U)}

\section{Introduction and Summary}

Nitrite is to be used to inhibit pitting corrosion during Extended Sludge Processing (ESP). The required nitrite concentrations are expressed as a function of the slurries' nitrate ion concentration and temperature. In the most dilute slurries, the nitrite inhibitor requirement is independent of the nitrate ion concentration and depends only on the temperature of the waste. The nitrate-independent concentration ensui es that there is sufficient inhibitor, in sludge slurries whose nitrate has been depleted by radiolysis, to prevent pitting corrosion induced by other corrosive anions (e.g., sulfate and chloride). The threshold nitrate concentration at which the nitrite level is expressed as a function only of temperature is $0.02 \mathrm{M}$.

A reduction in the nitrate threshold will lead to substantially increased operational efficiency in the final washing stages of ESP. A reexamination of the basis for the threshold level of $0.02 \mathrm{M}$ revealed that safe pitting inhibition of sludge slurries is possible with a threshold nitrate concentration of $0.01 \mathrm{M}$. The new nitrite limit for very low nitrate concentration slurries thus becomes

$$
\left[\mathrm{NO}_{2}^{-}\right]=0.00038 * 10^{0.041 \mathrm{~T}}
$$

where $\left[\mathrm{NO}_{2}^{-}\right]$is the concentration of nitrite in moles $/ \mathrm{L}$ and $\mathrm{T}$ is the temperature in degrees Celsius. This memorandum documents the basis for reducing the nitrate threshold to $0.01 \mathrm{M}$. 


\section{Discussion}

It has been shown that the anions nitrate, sulfate, and chloride in the aqueous phase of radioactive sludge slurries can induce pitting corrosion in carbon steel. ${ }^{1}$ These anions act independently, and at sufficiently high concentration of one anion with respect to the others, that one will determine or control the amount of inhibitor required to prevent pitting corrosion. The concentrations of corrosive anions in typical ESP waste slurries are such that nitrate is the dominant anion, and the nitrite inhibitor level is expressed as a function of the nitrate concentration. This formulation for the nitrite level is applicable over the expected range of sludge washing concentrations. However, nitrate is subject to radiolytic destruction. At low ESP solute concentrations, where the destruction rate has a significant effect on nitrate concentration, the nitrate concentration will fall to a value below which nitrate will no longer be inhibitor controlling. Experiments have shown that the sulfate anion (which is not subject to radiolysis) will replace nitrate as the inhibitorcontrolling anion. ${ }^{1}$

The minimum safe nitrite concentration could be expressed in terms of the nitrate concentration or the sulfate concentration depending on the ratio of the two.

However, to avoid the complexity of basing the inhibitor level on the concentration of aggressive anions other than nitrate, a minimum nitrite concentration has been specified that accommodates the possible effects of sulfate in low-nitrate slurries, and yet is not dependent on the sulfate concentration. ${ }^{2}$ This limit is expressed as

$$
\left[\mathrm{NO}_{2}^{-}\right]=0.00076 * 10^{0.041 \mathrm{~T}}
$$

where $\left[\mathrm{NO}_{2}{ }^{-}\right]$is the concentration of nitrite in moles/L and $\mathrm{T}$ is the temperature in degrees Celsius. It applies to ESP slurries with a nitrate concentration less than 0.02 $\mathrm{M}$, and in fact is the solution of the nitrite limit 4.d in the Technical Standards for sludge washing and storage at a nitrate level of $0.02 \mathrm{M}^{3}$

The selection of the threshold of $0.02 \mathrm{M}$ nitrate was based on an analysis of experiments on the effects of multiple aggressive anions in ESP slurries. ${ }^{2}$ Figure 1 shows one set of results of those experiments. The nitrite concentration required to prevent pitting in a washed sludge slurry is plotted against the nitrate concentration of the slurry, with all other slurry components held constant. In the high nitrate regime, the nitrite inhibitor level is proportional to the nitrate level. This proportionality is indicated by the hand-fitted diagonal line. However, at low nitrate concentrations, the nitrite required to inhibit pitting is constant, independent of the nitrate level, as indicated by the horizontal hand-fitted line. The two lines intersect at about $0.01 \mathrm{M}$. The threshold value of $0.02 \mathrm{M}$ was selected to lie safely within the nitrate-controlling regime.

It is clear from Figure 1 that a threshold value of $0.02 \mathrm{M}$ nitrate introduces a substantial measure of conservatism into the required inhibitor concentration for $\left[\mathrm{NO}_{3}{ }^{-}\right]<0.01 \mathrm{M}$. This conservatism comes with a cost of decreased washing efficiency during washing to the nitrate endpoint. It should be noted that the 
conservatism is in addition to the $50 \%$ safety factor built into the Technical Standard limit 4.d., the source of Equation 1. At $40^{\circ} \mathrm{C}$ the nitrite requirement according to Equation 1 is $0.033 \mathrm{M}$, whereas the data in Figure 1 at $\left[\mathrm{NO}_{3}{ }^{-}\right]<0.01 \mathrm{M}$ show inhibition at $0.008 \mathrm{M}$ nitrite.

Acceptable safety margins can be maintained with a reduction in the nitrate threshold to $0.01 \mathrm{M}$. The new limit for the nitrate-independent nitrite limit becomes

$$
\left[\mathrm{NO}_{2}{ }^{-}\right]=0.00038 * 10^{0.041 \mathrm{~T}}
$$

The nitrite requirement will then be reduced from $0.033 \mathrm{M}$ to $0.017 \mathrm{M}$, which still maintains a safety factor of more than $100 \%$ over the experimental data.

\section{References}

1. J. W. Congdon and J. S. Lozier, DPST-87-379, "Inhibition of Washed Sludge with Sodium Nitrite," April 7, 1987.

2. P. E. Zapp, WSRC-TR-90-512, "Effect of Temperature on the Nitrite Requirement to Inhibit Washed Sludge," November 2, 1990.

3. Technical Standard. Waste Tank Farms, DPSTS-241-5.03, Rev. 1 December 19, 1990. 
T. M. Monahon

Page 4

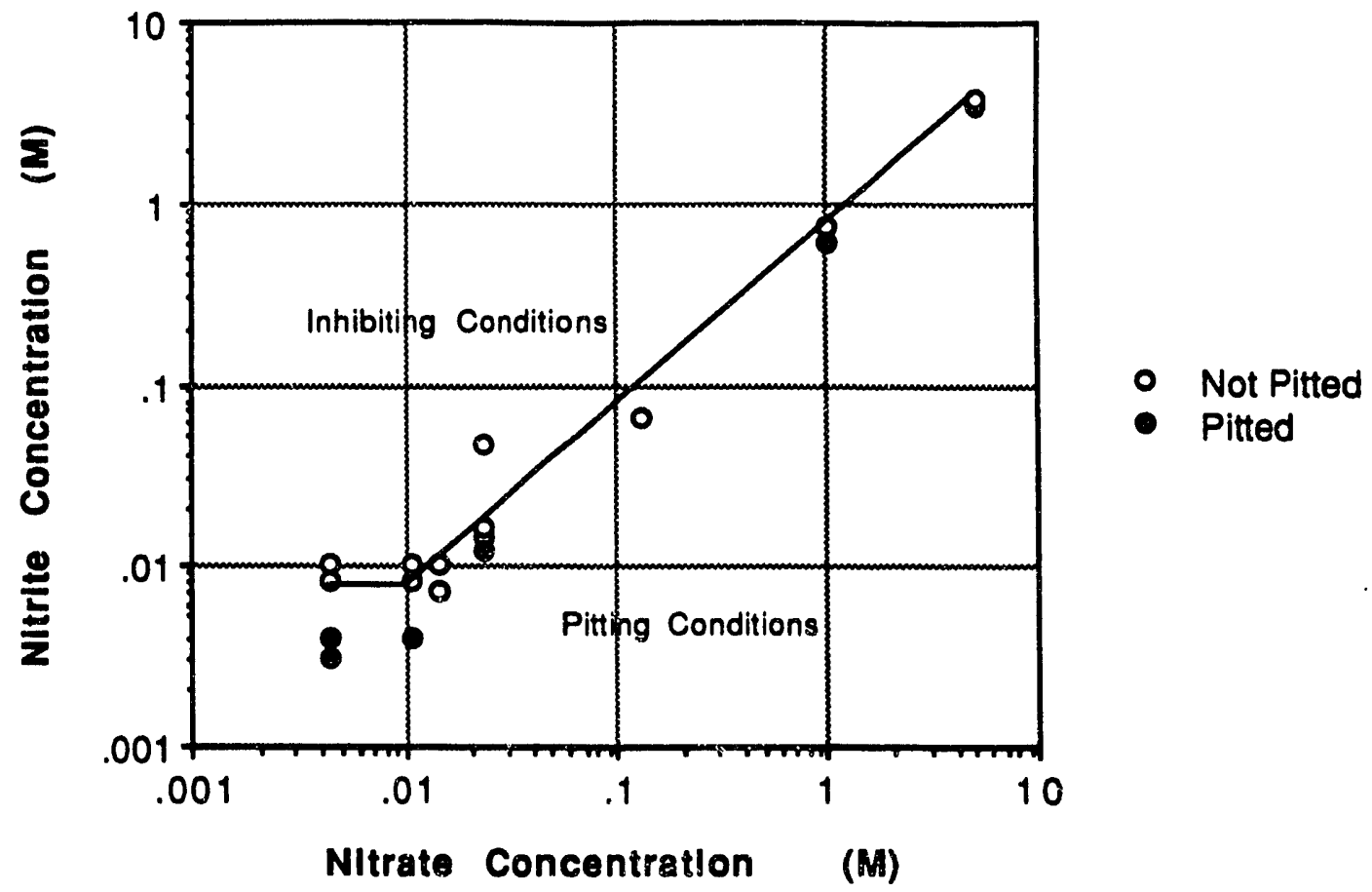

Figure 1. The corrosivity of simulated sludge slurry at $40^{\circ} \mathrm{C}$ containing the indicated concentrations of nitrate and nitrite. The boundary between inhibiting and pitting conditions was placed by hand. Data from Reference 1. 

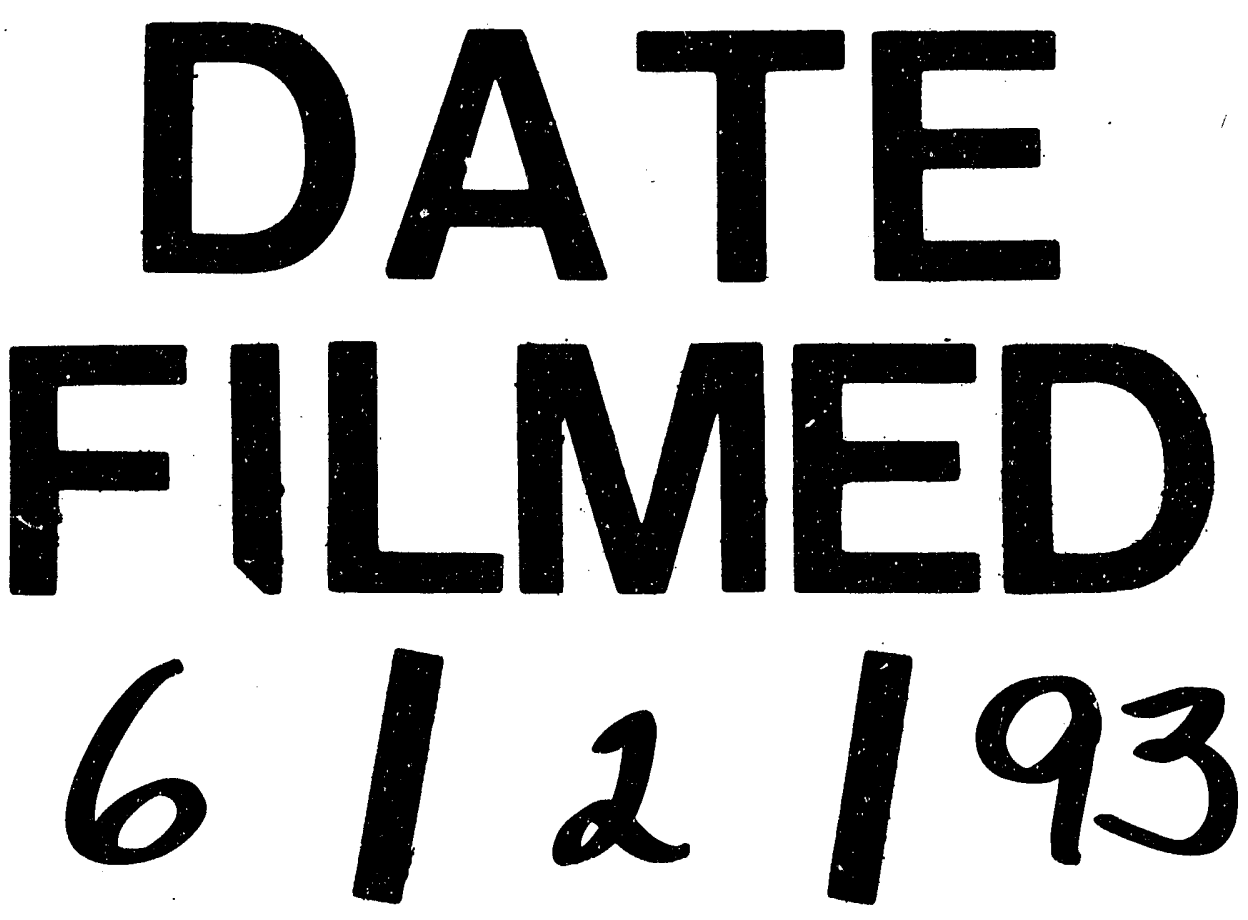


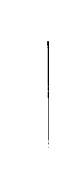

